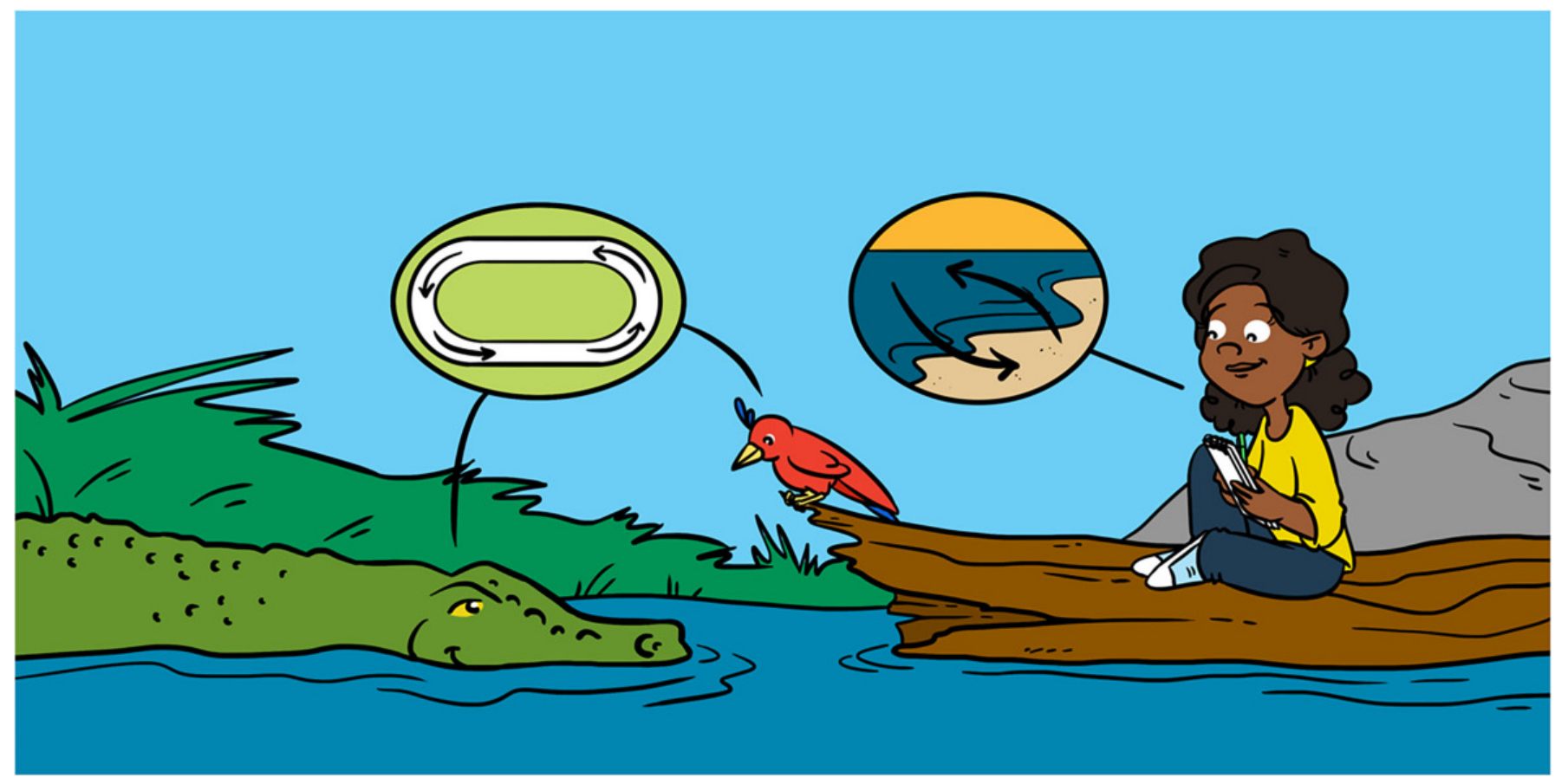

\title{
BREATHING IN BIRDS AND CROCODILES: WHAT'S DIFFERENT, WHAT'S THE SAME, AND WHY DOES IT MATTER?
}

\section{Alexandra McCartney ${ }^{1}$, Drake Mark ${ }^{1}$, Noah Gedja ${ }^{1}$, Maya Gibb ${ }^{1}$, Emily Adams ${ }^{1}$, Elias T. Polymeropoulos ${ }^{2}$ and Nicolle J. Domnik ${ }^{1,3^{*}}$}

${ }^{1}$ Department of Biomedical and Molecular Sciences, Queen's University, Kingston, ON, Canada

${ }^{2}$ Institute for Marine and Antarctic Studies, University of Tasmania, Hobart, TAS, Australia

${ }^{3}$ Department of Physiology and Pharmacology, Schulich School of Medicine and Dentistry, Western University, London, ON, Canada

\section{YOUNG REVIEWER:}

VLAD

AGE: 12
At first glance, crocodiles and birds appear to be two very different groups of animals. Crocodiles tend to inhabit marshes and wetlands, while most birds tend to nest on dry land or in trees. Not only do they look very different, but while crocodiles walk on all fours and are excellent swimmers, most birds fly. Interestingly, researchers have found remarkable similarities in the way crocodiles and birds breathe! Different from how humans breathe, both birds and crocodiles have one-way air flow through their airways, meaning that air moves in a circular path into the lungs and back out. This article compares the structures of the respiratory systems in birds and crocodiles. We also examine how their respiratory systems are specialized for their unique environments and activities. 
RESPIRATORY

SYSTEM

The structures within our body that perform the actions of moving air in and out of the body in order to allow gas exchange to happen.

\section{GAS EXCHANGE}

The process of taking oxygen into and removing carbon dioxide out from the body through diffusion; these gases are exchanged between the air and blood capillaries within the respiratory system.

\section{DIFFUSION}

The movement of particles of a gas, or liquid, from areas where there is a high concentration to areas where there is a low concentration.

\section{TIDAL BREATHING}

The movement of air in and out of the lungs along the same path; the air has to change direction to flow out along the same path that it entered by.

\section{UNIDIRECTIONAL}

\section{FLOW}

The movement of air in one direction through the lungs, in a relatively circular path, rather than the air being inhaled and then pushed out along the same path.

\section{FROM CROCS TO CROWS: HOW DO BIRDS AND CROCODILES BREATHE?}

Imagine being a bird. Although there are many different species, most birds spend their days flying in search of food, building nests, and avoiding predators. Now imagine being a crocodile. They live in hot, humid wetlands and spend their days swimming, moving over land, and basking in the sun. Crocodiles and birds clearly exhibit very different behaviors; however, the way these activities are powered is the same as in all types of animals. Animal cells require oxygen to create the energy they need to function. Oxygen obtained from the air travels through animals' respiratory systems where gas exchange happens. Gas exchange occurs when oxygen from the air that is breathed in flows into an animal's blood via a process called diffusion. In exchange, the carbon dioxide that cells produce as a waste product diffuses from the blood into the air and is breathed out.

Humans breathe in what is called a tidal breathing pattern. Much like the tides of the ocean, which approach the shore and then move back out to the sea by the same path, the air we breathe into our lungs switches directions and exits through the exact same path that it entered. However, both the bird and crocodile respiratory systems have what is called a unidirectional flow breathing pattern: air flows in mainly one direction, in a loop, through structures known as primary and secondary bronchi (Figure 1). Bronchi (also known as airways) are the tubes that act as the path for air flowing in and out of lungs. In this article, we will compare the respiratory systems of birds and crocodiles to understand how unidirectional flow helps these two very different types of animals.

\section{INSPIRATION: BREATHING IN}

As shown in Figure 2A, when a bird breathes in, air enters the respiratory system through a rigid, hollow tube surrounded by rings of cartilage (a stiff body tissue); this tube is the trachea [1]. In some birds, the trachea may form a loop to accommodate other airways; this feature may also help them produce sound [2-4]. The trachea is in the bird's chest and splits into two smaller tubes called primary bronchi as it gets deeper into the bird's body. These primary bronchi are muscular tubes that branch into the right and left lungs [1].

After air moves through the bird's primary bronchi and reaches the backs of the lungs, it travels into smaller, thinner tubes known as dorsobronchi. Dorsobronchi eventually turn into parabronchi, which are even thinner, straight tubes. Parabronchi eventually connect to ultra-thin tubes known as air capillaries. Air capillaries are where air comes into direct contact with small blood vessels called blood capillaries. This meeting of air and blood is where gas exchange takes place [2]. Oxygen is delivered to the blood through the thin barrier 
Figure 1

Comparison of tidal and unidirectional airflow patterns. Animals like mammals (e.g., humans, dogs, horses; left side of figure) use a tidal breathing pattern, where air enters and exits the two lungs via the same pathway (same trachea and same bronchi). In other words, the air has to reverse its direction to exit the same way it entered. This is similar to the ocean tides, where the water comes closer to the shore and then leaves the shore by the same pathway. In animals like birds and crocodiles (right side of figure), a unidirectional (one-way) breathing pattern is used. This means that air enters the respiratory system and passes through a one-way circuit after it has passed through the trachea, always moving in one direction, before exiting. This is similar to a racetrack, where the cars only drive in one direction.

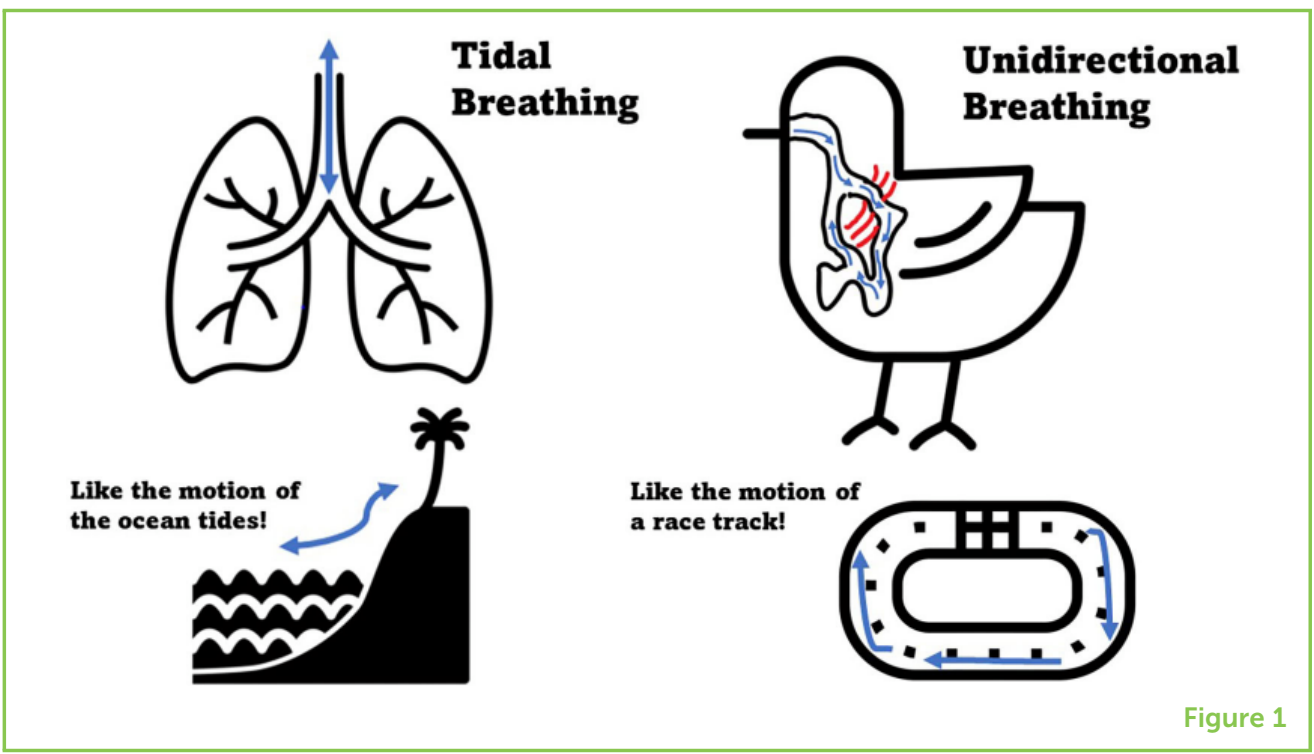

between the blood and air capillaries, while carbon dioxide moves from the blood into the air to be carried out of the body [1].

Air travels through a similar unidirectional pathway in crocodiles (Figure 2B). Much like birds, crocodiles have a trachea with rings of cartilage. In small crocodile species, the trachea may form a loop to accommodate other airways, similar to in some bird species [2-4]. Once in the trachea, air moves into the primary bronchi. These curve more sharply than those found in birds and look a bit like hooks in the two lungs [2]. Just like in birds, air inhaled by crocodiles flows from the primary bronchi into multiple dorsobronchi that branch near the backs of both lungs. From the dorsobronchi, air flows into parabronchi to deliver oxygen from air capillaries to blood capillaries. These parabronchi have the same shape and positioning as those found in birds but are larger than those of most bird species [2].

\section{AIR RESERVOIRS}

Birds have a unique respiratory feature. If the air in their primary bronchi is not going to be immediately used in gas exchange, it will move out from a primary bronchus and be stored in thin-walled sacs known as posterior air sacs. These air sacs do not appear in crocodiles. But if crocodiles can perform unidirectional respiration without the air sacs birds have, how do they store air when they need to hold their breath? Interestingly, scientists have found small spaces called locules in crocodile lungs, located close to where air sacs would be in birds. Crocodiles also have a region near the end of each primary bronchus known as the caudal sac-like structure, which takes care of air storage [2-4]. Thus, both birds and crocodiles have air-storage solutions! 


\section{Figure 2}

Simplified diagram of the respiratory system of birds (A) and crocodiles (B). The unidirectional (one-way) path that air takes going into and out from the body is illustrated by the blue arrows within the white spaces in each drawing, which represent the hollow airways and lungs of each animal. The process of gas exchange, which involves the diffusion of $\mathrm{O}_{2}$ (oxygen) and $\mathrm{CO}_{2}$ (carbon dioxide) between the air and blood capillaries, is highlighted in the purple inset. The term "cervical" refers to a location near the neck. "Ventral" refers to a location near the stomach or belly. "Posterior" refers to a location toward the rear of the animal, and "dorso-" refers to the animal's back.
A: Bird Respiratory System

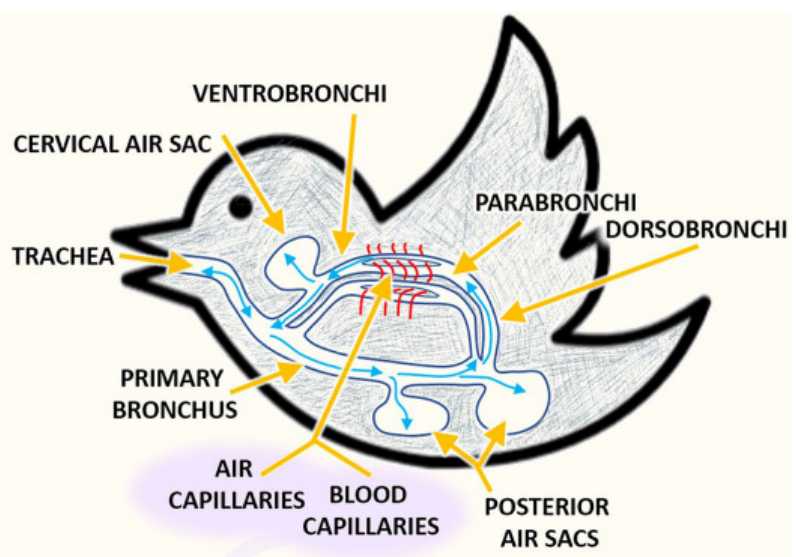

B. Crocodile Respiratory System

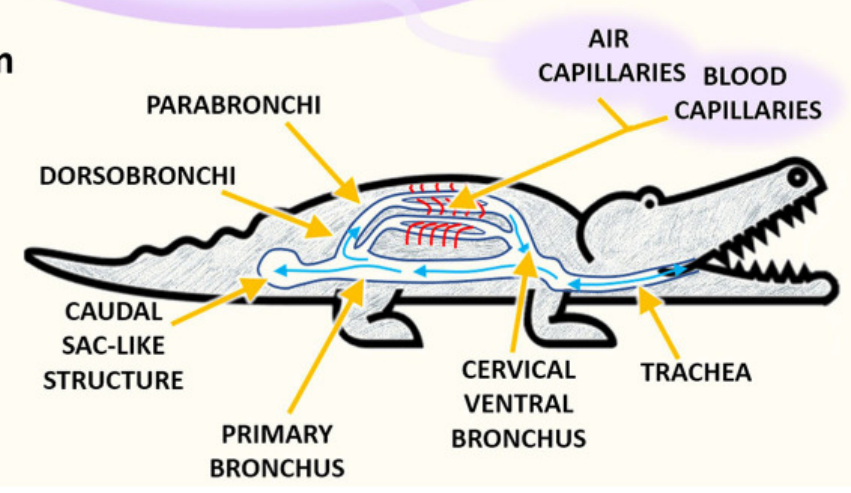

Figure 2

\section{EXPIRATION: BREATHING OUT}

When a bird breathes out, air moves from the posterior air sacs into the dorsobronchi and then into the parabronchi for gas exchange. Air that has already released oxygen into the blood and taken up carbon dioxide from the blood then moves from the parabronchi into bigger bronchi known as the ventrobronchi at the front (ventral) part of each lung. From there, it moves back out through the trachea, right where it came from [1]!

In contrast to birds, crocodiles have one main secondary ventral bronchus in each lung, known as the cervical ventral bronchus (CVB). Each CVB has a very large diameter, and scientists think this may be because air that has already undergone gas exchange can be temporarily stored in the CVB before leaving the trachea [2-4]. This 
Figure 3

Evolutionary tree showing the common ancestry between modern Crocodilia (crocodiles and alligators) and Aves (birds). Three hundred million years ago, birds and crocodiles slowly evolved from a common ancestor, Diapsida, into the species we see today. Diapsida itself had evolved from an earlier shared ancestor, called an ancestral amniote. There are over 17,000 known species of Diapsid on Earth today.

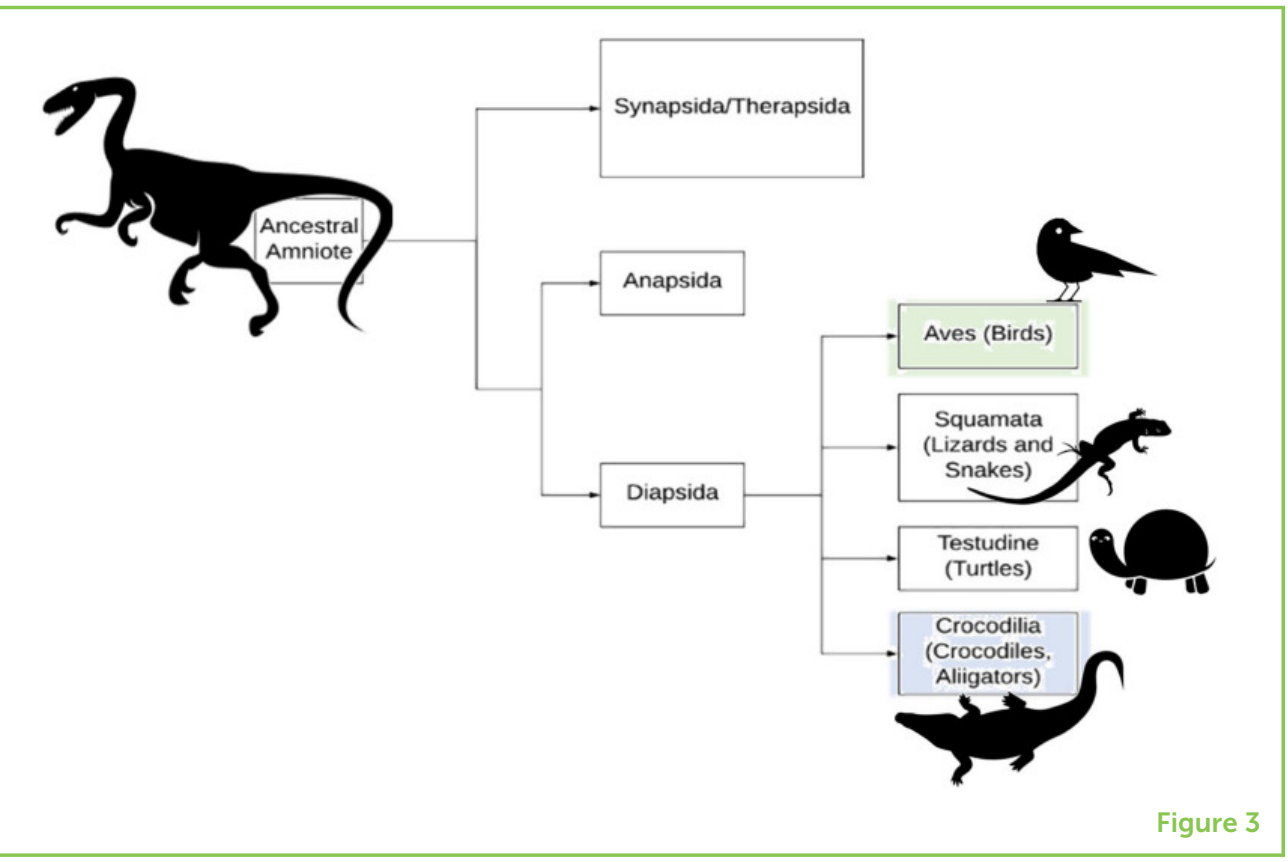

is important, since this air cannot exit the trachea while fresh air is entering the trachea from the outside. Valves help to ensure that air that has already undergone gas exchange only exits via the trachea during a breath out and does not compete with breaths in. Birds have air sacs connected to their ventral bronchi, known as cervical air sacs, for the same function $[3,4]$.

\section{AN EVOLUTIONARY CONNECTION}

Aerobic capacity is a term that is used to describe how much oxygen an animal (or person) can use when physically active. A well-trained long-distance cyclist, for example, has a high aerobic capacity and uses lots of oxygen when cycling to sustain very vigorous cycling. Birds fly, which requires a lot of energy. Therefore, birds typically have a high aerobic capacity. On the other hand, crocodiles are less active and have lower aerobic capacities. Despite this difference in aerobic capacity, the structure of bird and crocodile respiratory systems is similar, in part because they developed from a common evolutionary ancestor: dinosaurs (Figure 3)! The shared features of the respiratory systems of birds and crocodiles help these animals to use oxygen effectively in times when oxygen demand is high. These similarities evolved before birds and crocodiles evolved from their shared ancestor [2]. While crocodiles may look more like what we think of when we hear the word "dinosaur," it is well-accepted that birds evolved from dinosaurs. This is based on similarities in their skeletons, soft tissues, growth rates, reproduction, and behavior [5]. 


\section{ENDOTHERMIC}

Animals that can create their own body heat from energy sources like food and oxygen to stay warm are called endothermic or warm-blooded.

\section{ECTOTHERMIC}

Animals that depend on the temperature of their outside environment (e.g., air or water temperature) to warm up or cool down are called ectothermic or cold-blooded.

\section{ADAPTATIONS TO FLIGHT}

Birds need a highly effective respiratory system because flying requires a lot of oxygen! Like mammals, birds are endothermic (warm blooded) animals. This means their cells generate their own body heat, which also requires a lot of energy and oxygen. Luckily, birds have developed some very neat respiratory features to meet this high oxygen requirement. In a bird's gas exchange region, the blood and air capillaries are arranged crosswise over each other in the shape of an " $x$," with blood moving at an angle in relation to the fresh air in the air capillaries. This efficient arrangement is known as cross current gas exchange, and it helps the bird to maximize the amount of oxygen it can take from the air [6]. Because of the unidirectional flow of air in their respiratory systems, birds' airways do not need to expand and contract easily. This means that the tissue surrounding the airways can be stiffer and stronger than in other animals. This strong tissue protects the airways and helps support the very thin airway capillaries [7].

\section{ADAPTATIONS TO AQUATIC LIFE}

Unlike endothermic birds, crocodiles are ectothermic and cannot generate their own body heat; rather, they depend on the temperature of their environment: when it is warm, they are warm; when it is cold, they are cold. You will often find lizards sunning themselves to warm up. We also know that crocodiles tend to spend much of their time in the water, even completely submerged. Thus, the ability to hold their breath is critical. When crocodiles are hunting or hiding underwater, their lungs can act as an oxygen-storage area. Moreover, the movement and pressure of a crocodile's beating heart can help pump or mix the air in the lungs, further supporting their breath-holding abilities. This is very exciting, as recent studies have also found that, in some mammals, oxygen is pumped into the gas-exchange structures by the heart's movement as well as by the usual pressure of breathing $[3,4]$.

\section{FROM UNDERSTANDING TO ACTION: WHY STUDY THESE SPECIES?}

The crocodile and bird species we see today may look and behave very differently from each other, but their common ancestry means that their respiratory systems are quite similar! Unlike you and I, crocodiles and birds both have unidirectional airflow through similar respiratory structures. However, there are some key differences as well, which help crocodiles and birds to carry out their very different activities. A unidirectional respiratory system not only helps birds sustain flight but also helps crocodiles hold their breath for long periods. Studying the respiratory systems of these animals is important for many reasons: doing so not only teaches us about how connected 
even the most different-looking of species can be, but also provides us with valuable knowledge for helping to understand how animals interact with their natural environments. This type of knowledge is critical for supporting conservation efforts and can also provide inspiration for exciting new ways of tackling various biological or even biomedical challenges. There are still many mysteries to uncover about how various animal species breathe, with new structures, airflow patterns, and evolutionary relationships to explore. Now that you know more about bird and crocodile respiratory systems, what unanswered questions would you like to investigate?

\section{ACKNOWLEDGMENTS}

Figures in this review were created using a combination of PowerPoint and images publicly available through Creative Commons. The animal outlines and monochromatic line drawings used as the foundations for Figures 1, 2 were obtained from https://thenounproject.com/.

\section{REFERENCES}

1. Duncker, H.-R. 1974. Structure of the avian respiratory tract. Respir. Physiol. 22:1-19. doi: 10.1016/0034-5687(74)90044-9

2. Schachner, E. R., Hutchinson, J. R., and Farmer, C. 2013. Pulmonary anatomy in the Nile crocodile and the evolution of unidirectional airflow in Archosauria. PeerJ. 1:e60. doi: 10.7717/peerj.60

3. Farmer, C. G., and Sanders, K. 2010. Unidirectional Airflow in the Lungs of Alligators. Science 327:338-40. doi: 10.1126/science.1180219

4. Farmer, C. G. Similarity of crocodilian and avian lungs indicates unidirectional flow is ancestral for archosaurs. Integrative Comparative Biol. 55:962-71.

5. Brusatte, S. L., O'Connor, J. K., and Jarvis, E. D. 2015. The origin and diversification of birds. Curr. Biol. Rev. 25:R888-98. doi: 10.1016/j.cub.2015. 08.003

6. Scheid, P., and Piiper, J. 1972. Cross-current gas exchange in avian lungs: Effects of reversed parabronchial air flow in ducks. Respir. Physiol. 16:304-12. doi: 10.1016/0034-5687(72)90060-6

7. Maina, J. 2006. Development, structure, and function of a novel respiratory organ, the lung-air sac system of birds: to go where no other vertebrate has gone. Biol. Rev. Cambridge Philos. Soc. 81:545-79. doi: 10.1017/S14647931 06007111

SUBMITTED: 30 June 2020; ACCEPTED: 19 October 2021; PUBLISHED ONLINE: 12 November 2021.

EDITED BY: Ester Dias, University of Porto, Portugal

CITATION: McCartney A, Mark D, Gedja N, Gibb M, Adams E, Polymeropoulos ET and Domnik NJ (2021) Breathing in Birds and Crocodiles: What's Different, What's 


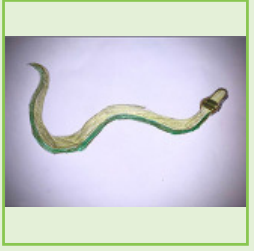

the Same, and Why Does It Matter? Front. Young Minds 9:578360. doi: 10.3389/ frym. 2021.578360

CONFLICT OF INTEREST: The authors declare that the research was conducted in the absence of any commercial or financial relationships that could be construed as a potential conflict of interest.

COPYRIGHT @ 2021 McCartney, Mark, Gedja, Gibb, Adams, Polymeropoulos and Domnik. This is an open-access article distributed under the terms of the Creative Commons Attribution License (CC BY). The use, distribution or reproduction in other forums is permitted, provided the original author(s) and the copyright owner(s) are credited and that the original publication in this journal is cited, in accordance with accepted academic practice. No use, distribution or reproduction is permitted which does not comply with these terms.

\section{YOUNG REVIEWER}

\section{VLAD, AGE: 12}

I like drawing, building LEGO, and cooking. I like learning Math and History. I also like to play with my cat and two rabbits. I want to be a herpetologist.

\section{AUTHORS}

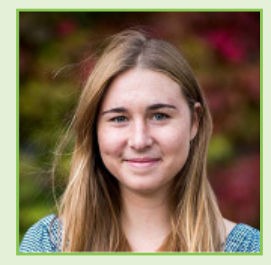

\section{ALEXANDRA MCCARTNEY}

Alexandra McCartney is a student at Queen's University studying life sciences. In her third year, she had the opportunity to take a physiology course focused on the human respiratory system, which piqued her interest in the topic; she is particularly intrigued by the ways in which the nervous system is linked to respiratory control. She has currently working as a summer research student in a cardiopulmonary physiology and sleep lab to further explore these interests. Alex enjoys challenging her own respiratory system through running, biking, and skiing in her free time!

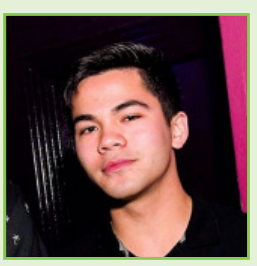

\section{DRAKE MARK}

Drake Mark is a student at Queen's University studying life sciences. His particular interest lies in the treatment of human cancers, but he has held an interest in wildlife since he was a child.

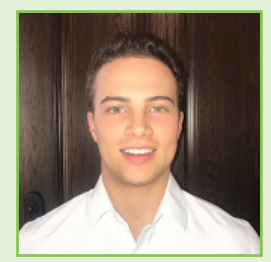

\section{NOAH GEDJA}

Noah Geja is completing his Bachelor of Science at Queen's University with a major in life sciences. Science is a passion of his and it fascinates him because it is always evolving. He enjoys histology, which is the study of the microanatomy of cells and tissues. In his free time, he loves to play golf, hockey, and ride his bike. 

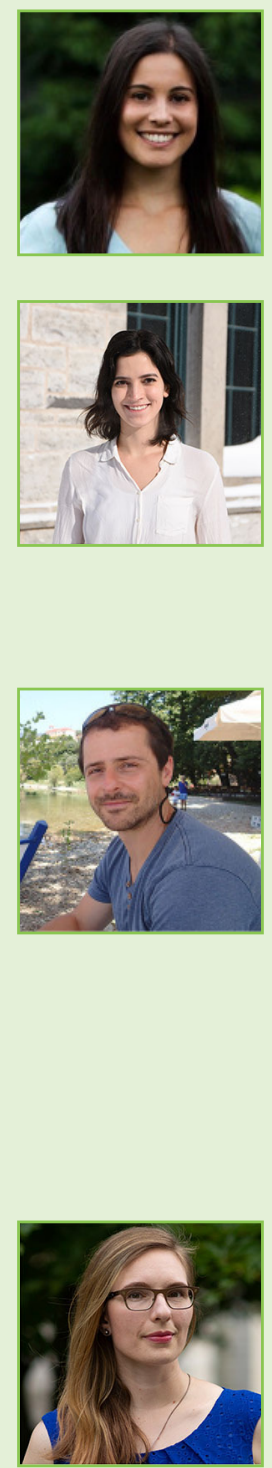

\section{MAYA GIBB}

Maya Gibb is a life sciences student at Queen's University in Kingston Ontario. During her undergraduate studies she has enjoyed taking a variety of physiology courses and has gained a strong interest in global health. In her spare time Maya enjoys hiking, traveling, hanging out with friends, and spending time at the cottage.

\section{EMILY ADAMS}

Emily Adams is an undergraduate student at Queen's University, Ontario where she studies life sciences. She is originally from Kelowna, British Columbia. Her goal after graduation is to go to medical school to become a doctor. She has worked as a student researcher on projects ranging from farming to cancer treatments. She also volunteers at a hospice and various student clubs. In her free time she likes to hike and take dance classes.

\section{ELIAS T. POLYMEROPOULOS}

Elias Polymeropoulos is a physiologist at the Institute for Marine and Antarctic Studies (IMAS) within the University of Tasmania (UTAS). After completing a Diploma in Biology at the Philipps- Universität Marburg (Germany), studying thermoregulatory mechanisms in marsupials, he completed a PhD in Tasmania, where he researched the physiology of Atlantic salmon, before working as an aquaculture biologist at IMAS. His research interests are physiological mechanisms of the respiratory and cardiovascular system that enable animals to adapt to different environments and the evolutionary processes underlying these adaptations. In his free time, Elias likes hiking, cooking and spending time on the beach.

\section{NICOLLE J. DOMNIK}

Nicolle Domnik has taught physiology and pathophysiology at Queen's University for 6 years and is a recently-appointed assistant professor at Western University. She loves sharing her passion for physiology with her students by helping translate research into real life. Her research has investigated the impact of chronic respiratory disease on the ability to breathe during sleep as well as how specialized neurons in our lungs sense our breathing movements and what is in the air. When she isn't thinking about lungs, she can usually be found experimenting in the kitchen, making music, enjoying the great outdoors, or seeking scientific advice from her most discerning reviewer: her cat. *nicolle.domnik@schulich.uwo.ca 